\title{
O IDEÁRIO CIENTÍFICO-PEDAGÓGICO DE FARIA DE VASCONCELOS (1880-1939) EM PROL DUMA ESCOLA NOVA E ATUAL
}

\author{
THE SCIENTIFIC-PEDAGOGICAL IDEALS OF \\ FARIA DE VASCONCELOS (1880-1939) FOR A NEW SCHOOL AND \\ CURRENT EDUCATION
}

\author{
Ernesto Candeias Martins \\ Doutor C/Agregação em Educação pela Universidade de Lisboa. \\ Professor de Mestrados na Escola Superior de Educação - Instituto Po- \\ litécnico de Castelo Branco, Castelo Branco, Portugal \\ ORCID: http://orcid.org/0000-0003-4841-1215?lang=pt
} ernesto@ipcb.pt

Resumo: Abordamos a figura de A. S. Faria de Vasconcelos, insígne representante do movimento da Escola Nova em Portugal, cujos princípios pedagógicos, por ele aplicados na escola de Bierges, na Bélgica, representaram a constituiçáo do seu sistema psicopedagógico e ganharam expressão em suas obras, intervenções e realizaçóes, com difusão na Europa e América Latina, em especial no período 1915-21. A partir de uma reflexão de caráter hermenêutico e do recurso a fontes primárias e secundárias, o texto propóe uma análise histórico-descritiva norteada pelos seguintes objetivos: i. analisar os fundamentos teório-práticos do sistema psicopedagógico, proposto por esse autor, e seus contributos à História da Educação - pedagogia contemporânea, educação popular, Movimento da Escola Nova; ii. compreender as bases pedagógicas da sua experiência em Bierges, particularmente quanto a sua inserção nos princípios do Movimento da Escola Nova e Ativa. Assim, realçamos os elementos fundamentadores da educaçáo integral dos alunos e a ligação dos princípios pedagógicos do autor ao movimento de renovação pedagógico e à história da educação portuguesa. Concluimos com a observação de que Faria de Vasconcelos deve figurar com destaque entre os pedagogistas de primeira plana nacional e mundial.

Palavras-chave: Educação Integral. Escola Nova. Faria de Vasconcelos. Pedologia. Psicopedagogia.

Aвstract: We approach the figure of A. S. Faria de Vasconcelos, outstanding representative of the New School movement in Portugal, whose pedagogical principles, for he applied at Bierges, in Belgium. This experience represented of the constitution of 
your psycho pedagogical system, expressed in his works interventions and experimental achievements, were diffusion in Europe and Latin America, in particular in the period 1915-21. From a reflection of character interpretation and the use of primary and secondary sources, the text offers a historical and descriptive analysis guided by the following objectives: to analyze the practical-theory fundamentals the psycho pedagogical system, proposed by this author, and their contributions to the History of Education (Contemporary Pedagogy), popular education, Movement of the New School; understand the pedagogical bases of your experience in Bierges, inserted in the application of the principles of Active and New School Movement .Thus, we have enhance the fundamentation elements of the integral education of students and the connection of the pedagogical principles of the author to the movement the of renovation pedagogy and the History of Education. We conclude with the observation that would make Faria de Vasconcelos must appear prominently among the pedagogy from first national and world flat.

Keywords: Integral Education. New School. Faria de Vasconcelos. Pedology. Psychopedagogy.

\section{Introdução}

A 1. ${ }^{a}$ República portuguesa (1910 a 1926) foi um manancial de medidas e iniciativas progressistas de extensão cultural, assistencial, jurídico-social e de modelos pedagógicos. Estão nesse universo educativo as universidades populares, a Universidade Livre, a criação de instituições assistenciais e educativas, a renovação da instrução, a legislação em prol da proteção à criança, as medidas de política social, as atividades comunitárias etc., que merecem ser rastreadas em estudos científicos. Pois foi nesse cenário de novas tendências em educação que foram divulgados vários métodos e estratégias de ensino (Montessori, Decroly, Plano Dalton, método de projetos, trabalho em grupos...), o sistema de self-government e os ideais da Escola Nova que se espraiam no pensamento, experiência e ação de António de Sena Faria de Vasconcelos (1880-1939), como um dos pioneiros da Educação Nova.

Esse escolanovista emerge num ambiente de início do período republicano no qual a ideia de educação popular se expande, em que o experimentalismo dá um contributo científico à abordagem do ato educativo e aos problemas pedagógicos escolares, tendo-se constituído, por direito próprio e reconhecimento internacional (europeu e latino-americano, em especial), numa figura de divulgação de ideias, experiências e açôes no 
campo da pedagogia moderna (FIGUEIRA, 2001). Por essa razão, tratase de um dos maiores vultos da História da Educação e da Pedagogia Contemporânea, em particular na área da Psicopedagogia, continuando indiscutivelmente atual nos dias de hoje. Notabilizou-se na área da Psicologia Experimental e da Pedologia portuguesa, este um movimento médico-pedagógico no qual se destacaram figuras como as de Aurélio da Costa Ferreira, na Casa Pia de Lisboa; Alves dos Santos, na Universidade de Coimbra; Adolfo Lima, na Escola-Oficina n. ${ }^{0} 1$ de Lisboa; Álvaro Viana de Lemos, António Sérgio e outros. Esse pedagogo português apresenta uma biografia vital, rica e diversa tal como sua obra e pensamento, que emergem no espaço temporal da época entre um Portugal de finais da Monarquia Constitucional de 1880-1902); uma Europa cheia de ideias e experiências pedagógicas - com destaque para Bélgica e Suíça (1902-15); uma América Latina - foco em Cuba e Bolívia (de 1915-20) - preocupada com a formação dos professores e a introdução dos ideais da Escola Nova; e, por último, no seu País, a partir de 1920, contribuindo com propostas de reforma do sistema educativo, alterações psicopedagógicas e educativas necessárias e no papel de orientação escolar e profissional na formação dos alunos (VASCONCELOS, 1921).

É assim que A.S. Faria de Vasconcelos foi um autêntico "pioneiro da educação do futuro", designação atribuída por Ferrière, no prefácio de sua obra Une École Nouvelle en Bélgique (VASCONCELOS, 1915, p. 14). Embrenha-se ativamente no Movimento da Escola Nova, estabelece amizade com grandes vultos da época e experimenta/aplica os princípios dessa educação inovadora na Escola de Bierges, perto de Bruxelas, entre 1912 a 1914. Depois, divulga essas ideias renovadoras como conferencista, pedagogo, professor e reformador educativo, quer na Suíça, Cuba e Bolívia quer, posteriormente, em Portugal, onde criou o Instituto de Orientação Profissional M. ${ }^{a}$ Luísa Barbosa de Carvalho, tendo sido seu diretor entre 1925 a 1939, e o Instituto de Reeducação Mental e Pedagógica (1929-31), para além de ter elaborado, em 1923, a proposta de reforma do sistema educativo português, conhecida por Reforma do Ensino de João Camoesas, e, ainda, ter sido um grande articulista de periódicos e revistas especializadas, por exemplo, Seara Nova, Revista Escolar, Brotéria e Revista da Educação (DIAS, 1969). 
Formou-se em direito na Universidade de Coimbra em 1900, seguindo a tradição familiar de pai e avô juristas, mas sentiu uma especial vocação pelas pedagogias modernas. Doutorou-se em Ciências Sociais na Université Nouvelle de Bruxelles, em 1904, exercendo nesse país belga (até 1914) e na Suíça (1915) funções docentes no âmbito das ciências da educação, sendo encarregado de cursos de Psicologia Experimental no Instituto J.J. Rousseau de Genebra, sob direçáo de Claparède e com uma forte amizade a A. Ferrière.

Em seu livro Problemas Escolares, Faria de Vasconcelos (1929, p. 13) explica o que entende por pedagogia [contemporânea], "[...] considerando-a com um caráter e um espírito nitidamente científico.” Por outro lado, utiliza uma série de ciências como a biologia, a antropologia, a psicologia, a sociologia, a moral e a arte, cujas aquisiçóes e métodos servem para melhor estudar, compreender, interpretar os factos e os problemas educativos e sociopedagógicos. Esses factos e problemas devem possuir um critério próprio, como factos naturais e positivos, por isso a pedagogia é uma ciência autónoma, com um corpo definido, normativa, métodos de descrição e explicação próprios, embora recorra às outras ciências que a auxiliam na sua missão. A pedagogia constituía o meio eficiente para elevar os educandos a esferas individualizadas e, ao mesmo tempo, socializadas (BRASIL, 1969). A educação era, para o nosso pedagogo, um todo integral que se desenvolve harmonicamente para a formação do homem integral. E nesse sentido a educação mental, que o preocupou em larga escala, constituía a base firme sobre a qual se alicerçavam todos os outros tipos de educação (ALVES, 1967).

O propósito da nossa reflexão hermenêutica e histórico-descritiva centra-se na figura e pensamento de Faria de Vasconcelos, tendo como norte (fontes primárias e secundárias) os seguintes objetivos: analisar os fundamentos do sistema psicopedagógico, proposto por esse autor, e seus contributos à História da Educação - Pedagogia Contemporânea, educaçâo popular e Movimento da Escola Nova, que foi um movimento renovador pedagógico europeu; ii. compreender as bases pedagógicas da sua experiência em Bierges, particularmente quanto a sua inserção nos princípios do Movimento da Escola Nova e Ativa, dando realce aos elementos fundamentadores da educação integral dos alunos e alguns dos aspetos de organizaçáo escolar propostos na mencionada experiência. Utilizaremos 
uma metodologia hermenêutica de análise tendo como fontes os volumes I (1986), II (2000), III (2006), IV (2009) e V (2010) das Obras Completas do autor, reunidas e analisadas por J. Ferreira Marques na Fundação Calouste Gulbenkian em sete volumes, para além de artigos publicados em revistas científicas, em especial na Revista Estudos de Castelo Branco (1969), teses e dissertaçóes académicas e outros documentos em arquivos (Biblioteca Nacional, Torre do Tombo, bibliotecas municipais de Castelo Branco e Cascais e Biblioteca do Museu do Teatro).

Nossas análises buscam destacar os contributos do educador português à educação nova, à escola única, à utilização de métodos ativos, bem como seu papel de orientação na formação de alunos e na organização escolar, atividades que impulsionaram a pedagogia de princípios do séc. XX, com impacto em vários sistemas educativos. Faria de Vasconcelos apostava numa sorte de educação integral, no valor espiritual do homem, na sua capacidade como ser atuante, fruto de uma educação integral, pois como dizia: “[...] vale a pena ser Homem." (VASCONCELOS, 1923, p. 223), desenvolvido no seu único poema inédito 'Sois un homme!' de 1921.

\section{O sistema psicopedagógico fundado na pedologia}

O estudo científico da criança é o princípio dos imperativos preferidos por Faria de Vasconcelos (1909), como caraterísticas da pedagogia de índole científica. De facto, a "[...] pedagogia como ciência da educação liberta-se do empirismo e envereda pelo método científico" (VASCONCELOS, 1921, p. 13), pelo experimentalismo científico que marca a pedagogia contemporânea. Desse princípio, surge o imperativo da "[...] educação psicológica e pedológica do professor." (VASCONCELOS, 1909, p. 12).

Esse insigne escolanovista segue o ideário da escola nova, preconizando a subordinação dos conteúdos programáticos do currículo, da processologia didascálica às necessidades e potencialidades individuais psicofísicas da criança e da adequação das didáticas específicas na formação escolar. É sabido que o fundamento da educação nova foi a ciência da criança (pedologia), concebida como ciência natural. De facto, a pedologia daquela época integra uma metodologia experimental de observação, 
indução e experimentação, de tal forma que se multiplicam as mensuraçôes (exames psíquicos e antropométricos, testes e despistagens escolares) e criam-se laboratórios de psicologia experimental. Faria de Vasconcelos introduziu a necessidade de se realizar diagnósticos pedométricos nas escolas (antropometria de Quetelet) examinando-se estatura, peso, perímetro torácico, diâmetro biocromial, cefalometria, força muscular etc. (CUNHA, 1997). Dessas observaçóes e mediçóes (influência da pedotecnia de Decroly) estabelece um quadro de caraterísticas dos fenómenos evolutivos do desenvolvimento físico e mental (VASCONCELOS, 1928).

$\mathrm{O}$ respeito pela natureza da criança e pelo seu crescimento físico constituía a base da lei pedológica (pedologia geral e diferencial), impondo-se, nesse âmbito, o dever de conhecê-la e preveni-la, de modo que o educador converte-se num orientador e higienista que "[...] vigia e favorece o desenvolvimento normal da criança." (VASCONCELOS, 1909, p. 20). Por isso, exigia-se como condicionante um ambiente envolvente físiconatural propício ao crescimento da criança, em que o educador/professor propunha atividades estimulantes: às suas energias físicas, por meio de ginástica/desporto e jogos; às capacidades intelectuais, propondo exercícios escolares, a lição das coisas, os trabalhos manuais, o ensino experimental das ciências naturais, a resolução de problemas no ensino das matemáticas etc. Ou seja, o educador/professor vai gradualmente ensinando a criança/ aluno a aprender a aprender fazendo. Por conseguinte, o nosso pedagogo apresenta, na sua obra e pensamento, um sistema de princípios caraterizadores do seu sistema psicopedagógico, destacando, por exemplo:

i. Princípio regenerador e edificante da educação. A educação tem uma capacidade regeneradora no ser humano: evolução do seu interesse sociológico para o biológico, psicológico e pedagógico (VASCONCELOS, 1909), mesmo com as crianças 'anormais escolares' e delinquentes, convertendo-se num poder 'emancipador' do desenvolvimento do ser humano (VASCONCELOS, 1936).

ii. Princípio do desenvolvimento (lei pedológica). O estudo científico da criança constitui o primeiro imperativo da pedagogia ou ciência da educaçáo. A base da educação e da escola nova era a ciência da criança (ciência natural), tendo como auxiliar a pedologia pela observação e experimentação. A criaçáo do meio propício ao normal 
desenvolvimento afigurava-se essencial, pois a partir daqui o educador incumbia-se de "[...] cuidar dos fatores que estimulassem as energias físicas e intelectuais da criança.” (VASCONCELOS, 1909, p. 33). Mas o educador deve, nessa ciência nova (pedologia), ser investigador, orientador e conhecedor das leis da pedologia geral, das diferenças e variedades reveladas pela pedologia diferencial quanto à sensibilidade, imaginação, atenção, memória, juízo e reatividade da criança.

iii. Princípio da autonomia da criança. Esta lei representa uma rutura com a teoria antropológica do 'homúnculo' (criança= adulto em miniatura) e da infância como fase de ascensão para o estado adulto. Para Faria de Vasconcelos (1909, p. 330), a criança é uma unidade e totalidade em si mesma significativa e, por esse princípio, superava-se esse "[...] pré-juízo do adulto" e incidiam as "[...] leis do desenvolvimento" aos interesses no ato educativo. Assim, destaca três fatores nucleares no crescimento mental da criança: o jogo parte lúdica que segue as teorias de Froëbel, Claparéde, Groos, Carr, Lange; a imitação pedagógica, relacionada com as condiçóes do ato humano - seguindo a teoria de Tarde, consciente e voluntário com a palavra e expressão, com a distinção entre educação e sugestão; os interesses, bem difundidos na pedagogia de Herbart, W. James, Decroly, Claparède e Luquet, sobretudo na relaçáo com o crescimento, a organização escolar e curricular (GOMES, 1984).

iv. Princípios antropológicos da continuidade e solidariedade psicofísica. Estes princípios decorrem do "[...] dinamismo psíquico do ser humano, em que a continuidade psicofísica, a diferença entre fenómenos físicos e psíquicos dependia do grau de desenvolvimento, da intensidade e complexidade, das expressôes diferenciadoras de um único processo evolutivo." (VASCONCELOS, 1909, p. 114) A base da atividade dos sentidos constituía a base da atividade psíquica, com destaque para a educação sensorial e os trabalhos manuais. $\mathrm{Na}$ verdade, a cultura integral do ser humano radica no princípio de continuidade e solidariedade das funçôes psíquicas e da atividade orgânica, obrigando à reflexáo e correção da orientaçáo intelectualista da educação. De facto, esses princípios implicavam a prioridade da educação física e sensorial em relação à intelectual, seguindo a 
linha psicogenética de Piaget, pois "[...] os sentidos são os primeiros instrumentos do conhecimento." (VASCONCELOS, 1909, p. 137). Contudo, no sentido de uma cultura sensorial global, havia a necessidade de cultivar a complexidade da memória que era "[...] a cúpula de todo o edifício intelectual” (VASCONCELOS, 1909, p. 139), onde decorrem os imperativos pedagógicos e a ação dos professores. Assim, privilegiava a atividade psíquica da associação de ideias, baseada na atração psicológica, da multiplicidade dos fatores da atenção, que é o fator primordial das operaçôes psíquicas. Isto é, tudo em função dos interesses e da natureza da criança.

v. Princípio do humanismo pedológico e antropológico no seu sistema. A dimensão humanista decorre da cultura integral, numa multidimensionalidade, integralidade e abertura a fatores essenciais à educação (currículo, métodos) e formação (orientação), numa apologia das virtudes pedagógicas e antropológicas: "O homem não é apenas um tesouro de conhecimentos, o seu valor não se mede unicamente pelo vigor da sua inteligência, pela soma do seu saber." (VASCONCELOS, 1926, p. 126).

Todos esses princípios expressam uma matriz epistemológica e filosófico-pedagógica no âmbito teórico-concetual e da práxis pedagógica de Faria de Vasconcelos, impregnados do naturalismo pedagógico de J.J. Rousseau, Pestalozzi e Fröebel, pelo qual a criança é um elemento original da natureza, pautada na lei do crescimento físico, intelectual, social, moral, estético, sexual etc., enfim, para o seu desenvolvimento integral, daí o destaque do nosso escolanovista para as funções psíquicas (atenção, hábito, memória, associação, consciência, inconsciente, inteligência...) (VASCONCELOS, 1921).

\section{Inovaçóes pedagógicas na educação integral da Escola de Bierges, na Bélgica}

A escola de Bierges-lez-Wavre (1912-14), perto de Bruxelas, considerada a Escola Nova modelo por A. Ferrière no Prefácio ao livro Une École Nouvelle en Belgique (VASCONCELOS, 1915), expressa o envolvimento 
social, escolar e comunitário dos alunos no aprender para e na vida prática (campo) e nos sentimentos de pertença 'à sua escola' eram caraterísticas de uma educação integral, pois aquela escola “[...] era um simples laboratório para investigaçóes pacientes e continuas [...] uma obra de experimentação e de análise permanentes." (MEIRELES-COELHO, 2012, p. 239). António Nóvoa (2005, p. 83) comenta que "[...] Depois de um século de teorias pedagógicas, importava, agora, explicar concretamente o que se fazia, esperando que esta ilustração fosse inspiradora e contribuísse para lançar a semente da escola nova", ou seja, no dizer desse historiador e atual embaixador de Portugal na UNESCO, a passagem das ideias inovadoras à prática implicariam a modificação dessas mesmas práticas num laboratório de experimentação e observação dos alunos. Para ser 'Nova' essa escola devia satisfazer, no mínimo 15 dos 30 requisitos propostos pelo Bureau Internacional des Écoles Nouvelles, mas Faria de Vasconcelos cumpriu 28 deles, excepto a coedução por estar proibida na Bélgica e a reorganização em grupos de 15 . Há uma série de premissas educativas que caraterizam as açôes e experiências pedagógicas de Faria de Vasconcelos em Bierges, constituindo uma sinfonia de cultivo geral da personalidade individual, personalizada, social e coletiva dos alunos, destacando-se os seguintes andamentos formativos:

a. Primeira premissa pedagógica: laboratório de pedagogia prática e ativa. A Escola desempenhava um papel inovador no âmbito da psicologia/pedagogia moderna, nos meios que punha em ação e das necessidades moderna da vida, praticando a fórmula: "[...] a escola às crianças." (VASCONCELOS, 1915, p. 14) Assemelhava-se a um internato situado no campo, agrupando os alunos em casas separadas (ambiente comunitário, lar familiar e regime de autogoverno), sob a influência do meio natural (natureza), o qual "[...] servia de auxiliar à sua vida escolar: cultura física, educação moral, cultura intelectual e artística." (VASCONCELOS, 1915, p. 17).

b. Segunda premissa: envolvimento dos alunos. Estes escolares envolviamse em tudo o que realizavam e aprendiam na escola, considerandoa 'é a nossa escola, fomos nós que a fizemos', daí desenvolverem um sentido de pertença, um sentimento e emoçóes no aprender a tempo inteiro, no qual as atividades curriculares e não curriculares 
contribuíam para a sua formação e cultura geral a partir da observação, indução, indagação e experimentação (sentido de J. Dewey), movidos pelos interesses, incrustados numa vida ativa comunitária (autogoverno) e familiar. Cada aluno partilhava ativamente na definição dos objetivos, programação, estratégias de implementação e (auto) avaliação (FERNANDES, 1978) e tinha poder de decisão. A aprendizagem tornava-se mais eficaz se os alunos soubessem gerir eles próprios o que aprendiam com interesse e gosto, resolver problemas e sistematizar ideias, implementando-as na prática diária. Encontramos nessa Escola Nova os processos de ensino-aprendizagem da literacia em ciências, matemáticas, línguas, trabalhos manuais, indagação e pesquisa de saberes práticos, cultura financeira (autogoverno escolar) e demais aspectos favorecedores da inclusão, numa perspetiva dual de educação e formação (MEIRELESCOELHO, 2005).

c. Terceira premissa pedagógica: sentimento de uma escola ativa perto da natureza e com atividades intelectuais, sociais e artísticas. Os alunos construíam, de acordo com suas necessidades, motivaçóes e interesses a sua (auto) aprendizagem, ao seu ritmo. Era um sentimento de pertença unido à escolha e organização livre e consciente, partindo da observação, ação e experiência da realidade concreta das coisas e dos factos (MEIRELES-COELHO, 2012), em que os trabalhos manuais e as tarefas integravam-se com outras atividades lúdicas, desportivas, sociais e intelectuais.

O trabalho educativo estava estribado nos princípios da escola para a criança, o que implicava uma cultura corporal e higiénica assente num sistema de vida comunitária, destacando-se o desenvolvimento de uma cultura geral, física, lúdica, desportiva e sociocultural na educação infanto-juvenil. De facto, incentiva-se a criança brincar, jogar e praticar atividades físicas e desportos como boxe, esgrima, luta greco-romana, corrida e saltos, exercícios de ginástica ao ar livre, visitas a pé ou de bicicleta, excursóes, campismo, o escutismo e atividades socioculturais. Todo esse conjunto de atividades desempenhava uma função de educação social escolar. Tudo era exercitado articulando-se com a lição das coisas (observação), com os trabalhos agrícolas e manuais complementando essa panóplia de exercícios, 
tarefas e ocupaçôes. A variedade dos trabalhos realizados, sua adaptação à idade das crianças, a alternância com a dimensão intelectual e moral imprimiam-lhes um valor educativo único para elevar o espírito.

d. Quarta premissa: educação integral versus cultura geral. Em Bierges, o ensino baseava-se em princípios pedagógicos adequados aos objetivos de uma educação integral e multilateral para a vida e na vida. Os meios educativos de efetivação dessa educação consistiam: na limitação do número de alunos em cada classe (turmas inferiores a 20); na adoção de um ensino comunitário ou coletivo compatibilizado com 'classes móveis', segundo os graus de desenvolvimento dos alunos nas diferentes matérias curriculares (previsto horário individual na organização escolar para certas matérias); distribuição organizativa dos alunos e matérias em 4 seçôes - preparatória, dos 2 aos 10 anos; geral, dos 11 aos 14; superior, dos 15 aos 17; especial, para os de 18-19 anos; instrução geral, igual para todos entre os 7-14 anos e, a partir dessa idade, segundo as tendências vocacionais com orientação profissional; avaliação dos trabalhos dos alunos com observaçôes psicopedagógicas e um relatório dirigido às famílias, com indicaçóes referentes à sua parte moral e social.

e. Quinta premissa: a escola nova organiza trabalhos manuais e livres para todos com objetivo educativo e utilidade individual e coletiva (VASCONCELOS, 1915). Nessa perspetiva, os trabalhos manuais representavam em Bierges uma valiosa iniciação à observação, à indução, ao experimentalismo e à prática do fazer que exigia, previamente, várias operações (trabalho de projeto, programação, gestão e cálculo dos custos), para além do conhecimento das ferramentas e matérias-primas. Nesse ambiente oficinal respirava-se cooperação e desenvolvia-se o poder de iniciativa, a participação dos alunos na criação de uma escola, de modo a sentiremna como sua. Os trabalhos manuais, como a cestaria, cerâmica, cartonagem, modelagem, encadernação, trabalhos em madeira e ferro, completavam o elenco dos exercícios físicos e contribuíam para o desenvolvimento físico, moral e intelectual do aluno. Os trabalhos livres iam ao encontro dos interesses e gostos das crianças, "[...] despertando-lhes o poder de iniciativa e o espirito 
inventivo e de engenho, destacando-se a lição das coisas e uma série de esforços individuais, tarefas comunitárias e ocupaçôes" (VASCONCELOS, 1915, p. 53) (agrícolas, criação de animais etc.) como fatores de educação social. O self-government, o desempenho de cargos sociocomunitários, os contributos individuais, a programação e organizaçáo do trabalho e das tarefas da comunidade, o funcionamento da assembleia de alunos e tudo o mais constituíam elementos primordiais de educação social para todos, independentemente da idade (MEIRELES-COELHO, 2005).

É estranho que um pedagogo de renome como António Sérgio, que esteve em viagem pedagógica no Instituto J.J. Rousseau de Genéve com a mulher Luísa Sérgio, tendo sido ministro da instrução em Portugal, defensor do autogoverno escolar e dos ideais da Escola Nova não incluísse a Escola de Bierges de Faria de Vasconcelos entre as escolas-modelo a criar em Portugal (GOMES, 1984). Lembramos que Faria de Vasconcelos publicou na Revista Escolar (ano 5, no 9, novembro de 1925) um artigo: $O$ selfgovernment na escola, no qual expôs todas as caraterísticas desse modelo de interação e governação pelos alunos

f. Quinta premissa pedagógica: a cultura do corpo, a higiene, a ginástica, jogos e a música auxiliares do ensino. $\mathrm{Na}$ Escola, a ginástica pedagógica e os exercícios físicos, os jogos e o desporto, as visitas (a fábricas, museus, monumentos), passeios/excursóes e acampamentos integravam-se em atividades não curriculares semanais que iam ao encontro das ideias médico-pedagógicas e de higiene escolar e social vigentes na época.

g. Sexta premissa pedagógica: ensino das ciências, matemáticas, da literacia, das linguas e artes. $\mathrm{O}$ ensino das ciências naturais era a charneira da educação intelectual dos alunos, principalmente dos 7 aos 10 anos, e ia além das físico-químicas, sociais e humanas, da zoologia, da geografia e da história etc. já que permitiam a aquisição de hábitos de trabalho, sentido crítico, pesquisa, entre outras capacidades. A partir das observaçôes regulares, da indução e das comparaçóes chegavam a generalizaçóes, a classificaçóes, a grupos sintéticos de saberes, a associaçóes de trabalhos manuais (desenho, 
cartonagem), ou seja, os alunos colocavam-se perante os fatos e os problemas concretos. Desse modo, as "[...] matemáticas promoviam a aplicação de métodos de observação e experimentaçáo à aquisição de noçôes essenciais", utilizando dados numéricos em muitas ocasiōes (MEIRELES-COELHO, 2012, p. 108). Faria de Vasconcelos (1915, p. 90) tinha em conta os estádios de desenvolvimento da criança, considerando a "[...] abstração matemática como um tempo essencial ao desenvolvimento da criança, sendo uma coordenada de toda a realidade", pois tudo era medido e calculado em todas as circunstâncias.

$\mathrm{Na}$ verdade, a didática apresentada nessa 'Escola Nova' tinha como núcleo de ensino as ciências naturais, para além das matemáticas, línguas, geografia, história, atividades interdisciplinares e demais ciências (VASCONCELOS, 1923). Relativamente ao estudo das línguas aplicavam-se os mesmos métodos de observação, experimentação, trabalho individual e em grupo (exercícios), incidindo no gosto de falar, de se expressar (comunicação oral, escrita), na linguagem e na dição. A leitura do mundo precedia a leitura da palavra, como ensinado por Paulo Freire tempos depois, daí que linguagem e realidade uniam-se dinamicamente. $\mathrm{O}$ conceito de literacia era aplicado seguindo uma "[...] série de meios, classes móveis, horários, concentração do trabalho, interdisciplinaridade das matérias, cultura geral e especialização profissional", ou seja, aquisição de saberes básicos (MEIRELES-COELHO, 2012 . p. 73), levando os alunos a servirse dos conhecimentos, a saber utilizá-los e aplica-los: "[...] ensinar o mínimo possível, fazendo com que descubra o máximo possível, num esforço pessoal, pesquisa e descoberta." (VASCONCELOS, 1915, p. 102).

Por outro lado, fazia-se despertar o gosto estético da criança, de maneira que o seu espírito respirasse beleza, como quem respira o ar puro. Os alunos organizavam exposiçóes, trabalhos artísticos e atividades musicais e de canto. Em relação às "[...] modalidades de educação artística praticadas, educação sexual e à coeducação" (MEIRELES-COELHO, 2012, p. 231) (náo incluída, uma vez que eram rapazes) eram tratadas com tato, franqueza e abertura. Em relação à educação moral, social e artística, Faria de Vasconcelos (1915) destacava a importância do ambiente envolvente, 
sua organização no processo estruturante da personalidade do aluno e na cooperação em todas as matérias, atividades e tarefas comunitárias, no sentido de uma educação integral.

h. Sétima premissa pedagógica: cultura geral e especialização profissional. O profissional deveria ter uma cultura geral, desde do ponto de vista técnico (habilidades e competências) como "[...] capacidade de atenção e reflexão, facultades criativas e meios de trabalho" (VASCONCELOS, 1915 , p. 82). Na parte de aprendizagem profissional havia uma variedade de oficinas, confiadas à responsabilidade de um aluno eleito democraticamente entre os mais capacitados, que cooperava nessa governação de aprendizagem dos colegas (CUNHA, 1997). Exaltava-se o valor moral dessa prática, não sem que houvesse alguns escolhos que eram resolvidos no sistema de autogoverno e de consciencialização do próprio aluno: aprender para uma profissão, sob orientação, para ser um profissional e cidadão responsável e produtivo.

Faria de Vasconcelos (1915, p. 71) reduz a três princípios fundamentais a educação: estudo das "[...] relaçôes da criança e do homem com o campo, base do ensino, sendo os trabalhos manuais o meio pedagógico indutor para (res) estabelecer a relação da criança com a vida, a natureza e o trabalho"; adaptação do ensino e da educação à evolução natural da criança, seguindo as suas necessidades, interesses, carências, curiosidades etc.; adaptação do ensino à evolução histórica das ciências, na base da evolução natural da espécie.

É no princípio da instrução educativa, superando a distinção entre educação e instrução, que se formava o espírito da criança, ensinandolhe o menos possível e fazendo encontrar o mais possível, pela pesquisa, indagação, esforço e descoberta. Entre os princípios da Escola Nova, com meios necessários e envolventes à educação integral, destacamos os seguintes: número restrito de alunos por turma; classes móveis e horários individuais; tempo de duração das aulas; concentração de um pequeno número de matérias e estudo num tempo fixado; interdisciplinaridade dos saberes na organização curricular; cultura geral e a especializaçáo profissional; metodologia de investigação e ensino; conferências (mensais) de alunos e professores; atividades extracurriculares, como excursôes, visitas e acampamentos; mecanismos de (auto) avaliação (CUNHA, 1997). Por conseguinte, a Escola de Bierges apresentava uma perspetivo 
dual de educação e formação, pondo em prática, não só os princípios essenciais, como preconizava ideias inovadoras que iam ao encontro dos interesses dos alunos, numa dinâmica de sucesso, empreendorismo, literacia produtiva e inclusão.

\section{A organizaçáo escolar nas instituiçóes educativas}

Ao nível da organização escolar nas instituições educativas, Faria de Vasconcelos dedicou-lhe uma atenção especial, já que para ele a organização interna de uma escola envolvia um conjunto de atividades subjacentes ao desenvolvimento do processo ensino-aprendizagem, de forma harmoniosa. Entre essas atividades mencionava, por exemplo: a divisão dos alunos por turmas, a elaboração de horários, o estabelecimento de normas relacionadas com a duração das aulas e dos recreios, a definição das metodologias de ensino a serem utilizadas pelos professores, as atividades extracurriculares propostas, a definiçáo dos programas de estudo para as várias disciplinas, a definição das regras e instrumentos de avaliação e classificaçáo dos alunos e a relação da escola com a família ou pais dos alunos.

Toda essa função de organização pedagógica revelava-se cada vez mais complexa, à medida que existia um número mais elevado de alunos por turma, com ritmos de aprendizagem diferentes. Cabia à escola a regulamentação das atitudes do pessoal educativo e auxiliar, assumindo-se como modelos reguladores dos comportamentos, atitudes e condutas dos alunos nos espaços escolares.

No que diz respeito à elaboração e aplicação prática dos horários escolares, essa organização relacionava-se com a seleção de cada área de conhecimento, ajustada a um tempo necessário para que o professor e os alunos realizassem as diferentes etapas de uma lição, que segundo Faria de Vasconcelos, citado no Vol. II de J. Ferreira Marques (2000, p. 189) consistia na seguinte metodologia: "[...] $10^{\circ}$ revisão da lição anterior; $2^{\circ}$ correção dos exercícios efetuados, incluindo os trabalhos de casa; $3^{\circ}$ explicação e desenvolvimento da lição nova; $4^{\circ}$ realização dos exercícios de aplicação, destacando-se a investigação e experiências, trabalhos manuais, gráficos, etc.". Um dos fatores a ter em conta quanto aos horários era o de destinar a manhã a disciplinas e áreas de estudo que fossem mais cansativas para os 
alunos, para além de se contemplar uma duração limitada para cada aula e pausas letivas e recreios. Essa duração das aulas apresentava um grande interesse pedagógico, já que a sua "[...] amplitude implicava o sentido de uma aula como fenómeno quantitativo e qualitativo" (MARQUES, 2000, p. 190) e, por isso, propunham-se estratégias e metodologias de ensino que evitassem o cansaço dos alunos e a perda de interesse pelos conteúdos lecionados. Naquela época, nosso pedagogo era apologista de que a aula tivesse uma duração variada em funçáo da idade e do ano de escolaridade dos alunos, aconselhando que fosse de curta duração e concentradas, evitando os ruídos dos recreios, podendo ser: "[...] $1^{\circ}$ ano com aula de 25 min.; 2. ${ }^{\circ}$ ano de $30 \mathrm{~min}$.; $3^{\circ}$ ano de $35 \mathrm{~min} . ; 4^{\circ}$ ano de $40 \mathrm{~min}$.; e para o $5^{\circ}$ e $6^{\circ}$ anos de $45 \mathrm{~min}$. O intervalo das aulas devia ser facultado aos alunos um recreio com uma duração de cerca de 10 min." (MARQUES, 2000, p. 191).

Faria de Vasconcelos (1934) expôs a conceção de vários psicopedagogos da época, relativamente à duração dos tempos letivos, por exemplo, menciona: Flak, que não admitia uma aula com duração superior a 40 min.; Kuborn, que defendia uma relaçáo entre duração da aula e grupo etário, sendo de 30 minutos para os de 8 anos; Carini, qua advogava que para alunos de 9 anos a aula devia ter mais ou menos 20 minutos; Chawick, que propunha uma aula em função da idade dos alunos, indo de 15 minutos para os alunos de 5 a 7 anos a 30 minutos para alunos entre 12 a 16 anos. Assim, para um bom desenvolvimento do processo ensinoaprendizagem era conveniente uma homogeneidade na seleção do grupo de alunos que constituíam uma turma, para que todos tivessem o máximo de proveito no aprender. Reconhecia Faria de Vasconcelos (ANO) que era difícil haver essa homogeneidade total dos alunos, pois era mais normal haver uma desigualdade de aptidóes intelectuais e ativas, uma "[...] desigualdade nas condiçôes de trabalho escolar na aula e em casa, falta de colaboração da família nas tarefas escolares" e/ou com as atividades na escola (MARQUES, 2000, 195). Havia, pois, procedimentos divergentes ou até contraditórios e, no caso da homogeneidade da turma, competia aos professores promoverem estratégias de adequação do ensino ao nível intelectual dos alunos, propondo-lhes tarefas adequadas ao seu nível de conhecimento e de aprendizagem (VASCONCELOS, 1921). Na verdade, além da natureza dos conteúdos programáticos do currículo e consagrado 
no programa escolar, existia a aplicação desses mesmos programas aos alunos, recorrendo-se a estratégias que conduzissem a uma adequada gestão e economia de tempo e que não levasse os alunos a um esforço excessivo (MARQUES, 2006). Daí que se tornava necessário consagrar a cada uma das unidades de aprendizagem ou temas do programa um número de aulas em harmonia com o seu valor educativo e com a utilidade que poderiam ter para o percurso escolar dos alunos (MARQUES, 2009).

$\mathrm{O}$ ensino e a pedagogia da época revelavam um desconhecimento dessas questóes e, por isso, Faria de Vasconcelos (1909, p. 85) exigia a sua adaptação à fisiologia e à psicologia da criança, de modo a que a organização escolar e curricular se inspirassem nessas "[...] necessidades do corpo e do espírito infantil.” Daí que nas escolas deveriam institucionalizar medidas de higiene escolar e médico-pedagógicas, de uso da caderneta escolar e relatórios de diagnóstico (observacional, pedotécnico etc.), para que a orientação do professor promovesse a evolução higiénica e físico-psíquica da criança (intuição sensível de Pestalozzi, exercício genético, funcional e de adaptação às necessidades de Claparéde, a biogenética, lei de Stern, Binet, entre outros) (NÓVOA, 2005).

\section{Algumas consideraçóes e contributos}

A extensa obra de Faria de Vasconcelos tem merecido alguns estudos académicos e eventos científicos esporádicos, mas precisa, ainda pelas ideias inovadoras e experiências psicopedagógicas desse pedagogo, de investigaçóes atentas e aprofundadas, quer pelo valor científico-pedagógico e psicológico para a História da Educação, quer pela sua atualidade em termos de ideias renovadoras para a escola (FIGUEIRA, 2001). O pensamento e o ideário desse escolanovista integra pesquisas experimentais, doutrinas e açóes de intervenção sobre questôes de pedagogia, psicologia, didática e educação social, e em muitas línguas estrangeiras. Para Faria de Vasconcelos, os conteúdos programáticos, plasmados nos programas escolares, deviam ser aplicados nos programas aos alunos, utilizando estratégias que conduzissem a uma boa gestão de tempo e pouco esforço. Nesse sentido, era necessário consagrar a cada um dos temas contemplados no programa escolar "[...] um número de aulas em harmonia com o seu valor 
educativo e com a utilidade que poderiam ter para a continuidade do percurso escolar dos alunos." (MARQUES, 2000, p. 197)

É óbvio que os temas psicopedagógicos mais importantes abordados por Faria de Vasconcelos $(19090,1921)$ estão recolhidos na obra Problemas Escolares; unindo-se às questôes de orientaçáo escolar e profissional e de psicotecnia o converteram num pioneiro da educação e orientaçáo profissional (VASCONCELOS, 1928). A sua capacidade de divulgação e intervenção, ao nível da política educativa (Reforma de João Camoesas, em 1923), materializada nas Bases para a solução dos problemas de Educação Nacional (MARQUES, 2000); de educação social e comunitária (escola municipalista) expressa no folheto Campos de jogos, Jardins-de-infância e escolas primárias tipo municipal (proposta à Câmara Municipal de Lisboa pelo vereador Alexandre Ferreira), a criação de bibliotecas escolares nas escolas e jardins públicos, as colaboraçóes em várias revistas, a ação inovadora no Instituto de Orientação Profissional de Lisboa (1925-36) e, ainda, a introdução de novos modelos de ensino e metodologias têm ainda hoje um grande alcance pedagógico na educação atual. (FERNANDES, 1978)

A dedicação de Faria de Vasconcelos (1931) à vertente da orientação profissional está inserida numa pedo-antropologia, relacionada com as questôes vigentes na época, por exemplo: de acidentes no trabalho, de segurança laboral e de carreiras fracassadas; do taylorismo, com a sua organização e métodos de trabalho e fatores vinculados às aptidóes psicofisiológicas; com a psicologia experimental (testes mentais, de aptidão e vocação); e as crises económicas e a guerra. Analisou estudos e estatísticas, muitas delas provenientes de EUA (Münsterberg), da Alemanha (Van Brabant), da França (Marcelo Frois) e nacionais que mostravam a má adaptação técnica, fisiológica e mental do trabalhador à profissão e ao mercado de trabalho, sendo muitas vezes as causas de acidentes, mas com a aplicação de métodos científicos de orientação, seleção vocacional e conhecimentos de aptidôes se podia diminuir tais riscos em 80\% (VASCONCELOS, 1928). Esse facto e a instabilidade profissional motivada pelo aborrecimento ou por não estarem na profissão adequada, por exemplo, a fadiga, a falta de aptidão, física ou mental, as circunstâncias de orientação profissional, após I Guerra Mundial (encontrar para os mutilados, inválidos, estropiados e inadaptados uma profissão compatível com as suas capacidades), entre ou- 
tros aspectos, exigiam uma formação e qualificação profissional em prol do progresso das naçóes.

Em definitivo, uma das preocupaçóes de Faria de Vasconcelos foi a orientação escolar e vocacional dos alunos, de modo a que eles conhecessem suas aptidóes, habilidades e/ou capacidades para a sua formação vocacional e para a aprendizagem de uma profissão (MARQUES, 2010).

Diga-se o que se disser do autor, das suas ideias, das suas realizaçóes, ou das suas mensagens pedagógicas, a verdade é que da sua rica personalidade foram deixados traços marcantes na sua extensa obra (MARQUES, 2009). Conhecedor invulgar do que a nível internacional se passava no campo da educação, desenvolveu entre nós uma intensa obra de divulgação dos novos ideais educativos e dos novos planos de ação didática, foi um apóstolo da Educação Nova, desempenhou um papel de relevo na renovação dos estudos pedagógicos em Portugal, teve um trabalho colossal na montagem do Instituto de Orientação Profissional e no progressivo aperfeiçoamento dos métodos de trabalho aí realizados.

Por conseguinte, apesar do esquecimento a que têm sido votados seus escritos, sua obra foi organizada por J. Ferreira Marques (1986, 2000, 2006, 2009 e 2010) ou pela tradução atualizada de Une École Nouvelle en Bélgique por Meireles-Coelho (2012), promovendo o aparecimento de alguns estudos académicos. Contudo, seus escritos, principalmente a parte referente à etapa em Cuba e Bolívia, sua correspondência, suas preocupaçôes didáticas com o trabalho dos professores são, entre outros, ainda hoje, ensinamentos por explorar. Assim, em Portugal, em que as ciências da educação, em especial a História da Educação [Social] e da Educação Especial, ocupam um lugar de relevo, o nome de Faria de Vasconcelos deve figurar com destaque entre os pedagogistas e psicopedagogos de primeira plana nacional, europeia e mundial.

\section{Referências}

ALVES, M. A ação pedagógica de Faria de Vasconcelos. Tese de Licenciatura Ciências Históricas e Filosóficas- Faculdade de Letras/Univ. de Coimbra). Coimbra: UC/FL, 1967. 
BRASIL, R. Faria de Vasconcelos e a evolução da pedagogia portuguesa. Estudos de Castelo Branco, Revista de História e Cultura, no 30 (1 de julho), 1969, p. 38-46.

CUNHA, A. Faria de Vasconcelos: Pensamento e Ação Pedagógica. Tese de Mestrado em Filosofia da Educação no Instituto de Educação da Univ. Minho. Braga: Universidade do Minho/IE, 1997.

DIAS, J. L. 'Itinerário Biobibliográfico de Faria de Vasconcelos'. Estudos de Castelo Branco-Revista de História e Cultura, no 30 (1 de julho), 1969, p. 83-109.

FERNANDES, R. O Pensamento Pedagógico em Portugal. Lisboa: ICALP/Coleção Biblioteca Breve, 1978.

FIGUEIRA, M. Um roteiro da Educação Nova em Portugal. Lisboa: Faculdade de

Psicologia e de Ciências da Educação da Universidade de Lisboa, 2001.

GOMES, J. F. Estudos de História e Pedagogia. Coimbra. Livraria Almedina, 1984.

MARQUES, J.F. Faria de Vasconcelos - Obras Completas, Vol. I. (1900-1915.) Lisboa: Fundação Calouste Gulbenkian, 1986.

MARQUES, J.F. Faria de Vasconcelos - Obras Completas, Vol. II (1915-1920). Lisboa: Fundação Calouste Gulbenkian, 2000.

MARQUES, J.F. Faria de Vasconcelos - Obras Completas, Vol. III (1921-1925). Lisboa: Fundação Calouste Gulbenkian, 2006.

MARQUES, J.F. Faria de Vasconcelos - Obras Completas, Vol. IV (1925-1933). Lisboa: 
VASCONCELOS, A. S.F. Didáctica das Ciências Naturais. Paris/Lisboa: Livraria Ailaud e Bertrand, 1923.

VASCONCELOS, A. S.F. O Instituto de Orientação Profissional 'Mara Luisa Barbosa de Carvalho. Lisboa: Tipografia Torres, 1926.

VASCONCELOS, A. S.F. O exame psicológico. Boletim do Instituto de Orientação Profissional (Lisboa) (1. a série), no 1, p. 51-65, 1928.

VASCONCELOS, A. S.F. Problemas Escolares. 2a ed. Lisboa: Seara Nova, 1929.

VASCONCELOS, A. S.F. Liçôes de pedologia e pedagogia experimental. $2^{\text {a }}$ ed. Lisboa: Antiga Casa Bertrand, 1934.

VASCONCELOS, A. S.F. Delinquência e Inteligência nos adolescentes. Lisboa: Livraria Clássica Editora, 1936.

Recebido em 20 jul. 2018 / Aprovado em 5 dez. 2018

\section{Para referenciar este texto:}

MARTINS, E. C. O ideário científico-pedagógico de Faria de Vasconcelos (18801939) em prol duma escola nova e atual. EccoS - Revista Científica, São Paulo, n. 48, p. 363-383. jan./mar. 2019. Disponível em: <https://doi.org/I0.5585/EccoS.n48.5884〉>. 
